\title{
CARACTERIZACIÓN PRELIMINAR CON MICROSATÉLITES DE LA COLECCIÓN GUATEMALTECA DE FRIJOL COMÚN TREPADOR ${ }^{1}$
}

\author{
Karla Melina Ponciano-Samayoa², Julio César Villatoro-Mérida², Luis Gerardo Molina-Monterroso
}

\section{RESUMEN}

Caracterización preliminar con microsatélites de la colección guatemalteca de frijol común trepador. El objetivo de este estudio fue caracterizar con microsatélites una colección de 558 accesiones de frijol voluble guatemalteco. En el Instituto de Ciencia y Tecnología Agrícolas (ICTA), en el periodo enero 2008 a junio 2009, con base en seis marcadores microsatélites, se analizaron agrupamientos y diversidad genética dentro de los grupos de frijol. Todos los loci analizados fueron polimórficos, se detectaron 25 alelos con un promedio de 4,12 alelos por marcador. El análisis de similaridad detectó genotipos duplicados que al ser eliminados dio lugar a una colección reducida de 261 muestras diferentes (46,8\% de la original). Los análisis de similaridad y correspondencia identificaron 12 grupos, incluyendo un control andino. La diversidad genética de Nei para la colección reducida fue 0,4310 , y la diferenciación genética (Gst) de 0,5747 . La diversidad genética entre los grupos $(57,5 \%)$ fue mayor que la detectada dentro de los grupos $(42,5 \%)$. Las distancias genéticas entre grupos se calcularon en un rango de 0.1566 a 1,6205 . Un alto nivel de heterocigosidad fue observado.

\begin{abstract}
Preliminary microsatellite characterization of Guatemalan climbing beans. The objective of this study was to characterize a collection of 558 accessions of Guatemalan climbing beans. The work was conducted at ICTA during January 2008/June 2009, using six microsatellite markers, to analyze clustering and to evaluate genetic diversity among groups. All loci were polymorphic, detecting 25 alleles with average of 4.12 alleles per marker. Similarity analysis detected duplicated genotypes, which were eliminated and resulted in a reduced collection with 261 dissimilar samples (46.8\% of the original collection). Similarity and correspondence analysis identified 12 groups, including an Andean check. The genetic diversity based on Nei's index for the reduced collection was 0.4310 , and the genetic differentiation (Gst) was 0.5747 for the entire collection. Genetic diversity between groups $(57.5 \%)$ was greater than within groups (42.5 $\%)$. Genetic distances between groups ranged from 0.1566 to 1.6205. A high level of heterozygosis was observed.
\end{abstract}

Key words: Phaseolus vulgaris L., Guatemala, genetic diversity, similarity, clustering.

Palabras clave: Phaseolus vulgaris L., Guatemala, diversidad genética, similaridad, agrupamientos.

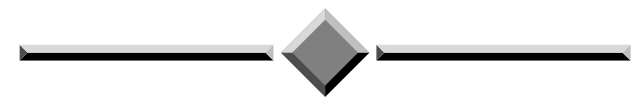

1 Recibido: 25 de junio, 2009. Aceptado: 16 de noviembre, 2009. Proyecto de investigación del Laboratorio de Biotecnología y el Programa de Mejoramiento Genético del Frijol. - ${ }^{2}$ Laboratorio de Biotecnología y Programa de Mejoramiento Genético del Frijol. Instituto de Ciencia y Tecnología Agrícolas ICTA. Km. 21.5 Carretera al Pacífico, Bárcenas, Villa Nueva, Guatemala, C.A. kponciano@icta.gob.gt; biotecnologia@icta.gob.gt; juliocevillatoro@hotmail.com 


\section{INTRODUCCIÓN}

El frijol común (Phaseolus vulgaris L.) es la legumbre alimenticia más importante a nivel mundial (Díaz y Blair 2006). En las zonas rurales más pobres de Guatemala, su cultivo se convierte en la actividad económica más rentable pues es fuente de ingresos al mismo tiempo que cubre las necesidades básicas de sus productores.

La recolección y conservación de germoplasma de frijol voluble guatemalteco ha constituido el primer paso para un prometedor futuro de investigación. En Guatemala se han realizado recolecciones de frijol silvestre y cultivado por Gentry (1966), Cojulum (1970), Freytag (1978) y Rodríguez (1982). En el Centro de Investigación del Altiplano de ICTA en Chimaltenango se conserva in situ una colección de aproximadamente 600 materiales de frijol voluble, provenientes principalmente de las recolecciones de Cojulum y Freytag, que representan diferentes localidades del altiplano guatemalteco y constituyen germoplasma valioso para el Programa de Mejoramiento Genético de Frijol del ICTA. Estas accesiones han sido conservadas en el Banco de Germoplasma a pesar de que lamentablemente carecen de datos de pasaporte, de manejo y de identificación fenotípica (Orellana et al. 2006).

Orellana et al. (2006) realizaron una caracterización agromorfológica preliminar que determinó que en la colección se encuentran las especies Phaseolus vulgaris L., Phaseolus coccineus L. y Phaseolus polyanthus Greenman. La recolección de datos agromorfológicos se limitó a 558 materiales pertenecientes a $P$. vulgaris en una localidad durante un año, utilizando el descriptor varietal del CIAT para 34 variables (12 cuantitativas y 22 cualitativas) registradas en las fases de germinación, madurez fisiológica y de cosecha. El análisis estadístico de la matriz básica de datos permitió discriminar entre individuos y explicar la variabilidad existente, formando cinco grupos de accesiones con un nivel de $71 \%$ de similaridad. No se identificaron duplicados, y no se estableció un orden por relación fenotípica. Lo importante de esta caracterización fue que se corroboró la especie y el hábito de crecimiento de todas las accesiones.

Ante el interés de comenzar un programa de mejoramiento genético con estos materiales, surge la necesidad de generar más información sobre el valor genético de la población y se propone una caracterización molecular que permita identificar duplicados, detectar genes de interés, asociarlos con sus características agronómicas y generar una colección núcleo que represente toda la diversidad genética y maximice los recursos para conservarlos (Van Hintum et al. 2003).

Los microsatélites (también conocidos como secuencias simples repetidas -SSR) son arreglos de motivos de uno a cinco nucleótidos repetidos uno de tras de otro. Se caracterizan por su hipervariabilidad, abundancia, reproducibilidad, herencia mendeliana, y codominancia (Gaitán et al. 2002). Son ampliamente utilizados para la caracterización molecular de frijol por su habilidad para detectar polimorfismos debidos a altos niveles de mutación en secuencias altamente conservadas. Son ventajosos porque detectan un número mayor de polimorfismos comparado con otras técnicas como RAPD y AFLP, explicando la diversidad existente y discriminando entre individuos (Blair et al. 2007). Se dice que son genómicos cuando han sido identificados a partir de bibliotecas genómicas y forman parte de regiones no codificantes, y pueden tener una naturaleza génica cuando forman parte de regiones que codifican para proteínas, por lo que generalmente son desarrollados a partir de secuencias expresadas o secuencias genéticas (Blair et al. 2003).

Un gran número de marcadores SSR han sido desarrollados a partir del genoma del frijol y algunos como BM160 y BM201 (Gaitán et al. 2002) son capaces de discriminar entre especies de $P$. vulgaris L., $P$. coccineus L. y $P$. polyanthus Greenman. Se debe resaltar que los microsatélites constituyen una técnica basada en PCR altamente reproducible, robusta e informativa, de fácil implementación en laboratorios de medianos recursos siempre y cuando se utilicen en cultivos ampliamente estudiados, como es el caso del frijol (Ferreira y Grattaplagia 1998). Un análisis de diversidad completo y muy confiable se obtiene de amplificar por lo menos 30 microsatélites visualizando con tinción con plata (Creste et al. 2001) en combinación con otras técnicas de detección como fluorescencia (Blair 2008) $)^{4}$

El objetivo de este trabajo fue caracterizar con microsatélites una colección de 558 accesiones de frijol voluble guatemalteco.

4 Blair, M. 2008. CIAT. Palmira, Colombia. 


\section{MATERIALES Y MÉTODOS}

\section{Material vegetal}

De la colección nacional de frijol voluble conservada en el Banco de Germoplasma del Instituto de Ciencia y Tecnología Agrícolas (ICTA) se analizaron 558 materiales de la especie $P$. vulgaris, en el periodo enero 2008 a junio 2009. Debido a que carecen de datos descriptivos y de pasaporte, las accesiones fueron asignadas con un número correlativo según el listado presentado en la caracterización agromorfológica realizada por Orellana et al. (2006), la cual dividió la colección en cinco grupos con base en descriptores fenológicos y cuantitativos. Los genotipos controles fueron proveídos por la Unidad de Recursos Genéticos del CIAT: tres accesiones silvestres de Guatemala provenientes de Sacatepéquez (G19908), Chimaltenango (G50504) y Quetzaltenango (G50507); y una accesión andina proveniente de Perú (G19833). Se tomaron cinco semillas al azar de cada material y se germinaron en invernadero.

\section{Extracción, verificación de integridad y cuantifica- ción de ADN}

Después de ocho días de siembra, $200 \mathrm{mg}$ de una mezcla de hojas trifoliares fue macerada con pistilos y nitrógeno líquido dentro de tubos de microcentrífuga de 1,5 $\mu \mathrm{l}$. El polvo obtenido se sometió al protocolo de extracción propuesto por Da Silva (2003). Se incubó a $65{ }^{\circ} \mathrm{C}$ por 30 minutos con $500 \mu \mathrm{l}$ de buffer CTAB con agitación constante. Se recuperó la fase acuosa de dos extracciones consecutivas con cloroformo: alcohol isoamílico $(24: 1)$. Esta se incubó a $37{ }^{\circ} \mathrm{C}$ por 30 minutos con $15 \mu \mathrm{l}$ de ribonucleasa A $10 \mathrm{mg} / \mathrm{ml}$. Luego se incubó por 20 minutos a $50{ }^{\circ} \mathrm{C}$ con $15 \mu 1$ de proteinasa K $20 \mathrm{mg} / \mathrm{ml}$. Se precipitó el ADN con $1 \mathrm{ml}$ de etanol absoluto a $-20{ }^{\circ} \mathrm{C}$. Se pescó el ADN con ayuda de una punta de micropipeta y se lavó con etanol al $70 \%$ centrifugando por 10 minutos a 13.000 rpm. El precipitado resultante se resuspendió en 150 $\mu \mathrm{l}$ de buffer TE (10 mM Tris-HCL, $1 \mathrm{mM}$ EDTA, pH $8,00)$ y se almacenó a $4{ }^{\circ} \mathrm{C}$. La integridad del ADN fue verificada cargando $10 \mu \mathrm{l}$ en un gel de agarosa al 0,8 $\%$. Las muestras fueron mezcladas con amortiguador de carga y corridas por una hora a $100 \mathrm{~V}$, y se tiñó con bromuro de etidio. A partir de diluciones 1:200 se cuantificó el ADN en un espectrofotómetro Bio-Rad SmartSpec3000 con un factor de conversión A260nm $1,0=50,0 \mu \mathrm{g} / \mathrm{ml}$. La calidad del ADN se determinó a partir de la razón A260/A280. El ADN se diluyó a 20 $\mathrm{ng} / \mu \mathrm{l}$ para las siguientes amplificaciones (Ponciano 2004).

\section{Amplificación y visualización de microsatélites}

En todas las muestras se analizaron seis microsatélites cuya descripción se resume en el Cuadro 1. Se escogieron tres genómicos y tres génicos, distribuidos en todo el genoma del frijol y que han sido ampliamente evaluados en estudios de diversidad genética (Gaitán eet al. 2002, Blair et al. 2006, Blair et al. 2007), estructura racial (Díaz y Blair 2006) y mapeo genético (Yu et al. 2000, Blair et al. 2003). Esta elección se hizo con el objetivo de detectar la mayor

Cuadro 1. Descripción de los microsatélites utilizados en la caracterización de la colección de frijol voluble de Guatemala. Guatemala, febrero 2008.

\begin{tabular}{lcccc}
\hline \multicolumn{1}{c}{ Asignación / Referencia } & Descripción & Motivo & $\begin{array}{c}\text { Tamaño producto } \\
(\mathbf{p b})\end{array}$ & Th $\left({ }^{\circ} \mathbf{C}\right)$ \\
\hline BM160*/ Gaitán et al. $(2002)$ & Proteína hipotética & $(\mathrm{GA})_{15}(\mathrm{GAA})_{5}$ & 211 & 52 \\
BM201*/ Gaitán et al. $(2002)$ & --------------- & $(\mathrm{GA})_{15}$ & 102 & 50 \\
BMd20**/ Blair et al. $(2003)$ & Endoquitinasa & $(\mathrm{TA})_{5}$ & 123 & 47 \\
J04555**/ Yu et al. $(2000)$ & Quinasa -1 & $(\mathrm{CTT})_{3}(\mathrm{~T})_{3}$ & 152 & 48 \\
M75856*/ Yu et al. $(2000)$ & Proteína-3-patogénesis & $(\mathrm{GA})_{11}$ & 157 & 47 \\
BMd36*/ Blair et al. $(2003)$ & Clon RAPD & $(\mathrm{TA})_{8}$ & 164 & 47 \\
\hline
\end{tabular}

*Fuente: genómico, **Fuente: génico. Abreviaturas: Temperatura de hibridización (Th), pares de bases (pb). 
cantidad de polimorfismos, combinando aquellos que detectan muchos alelos con otros que detectan menos pero que ofrecen diferentes niveles de información (Díaz y Blair 2006). Estos marcadores fueron amplificados por medio de PCR convencional en placas de 96 pozos en un termociclador ATC401 Apollo CLP. El programa utilizado consistió en una desnaturalización inicial a $94{ }^{\circ} \mathrm{C}$ por cinco minutos; después 30 ciclos de desnaturalización a $94^{\circ} \mathrm{C}$ por 30 segundos, seguido de hibridización a la temperatura (Th) indicada en el Cuadro 1 para cada uno de los marcadores por un minuto y una elongación a $72{ }^{\circ} \mathrm{C}$ por un minuto; terminando con una elongación final a $72{ }^{\circ} \mathrm{C}$ por cinco minutos. La mezcla de reacción fue de $25 \mu$ l finales que contenían $100 \mathrm{ng}$ de ADN genómico, $1 \mathrm{X}$ buffer PCR, 2,5 mM de $\mathrm{MgCl}_{2}, 400 \mu \mathrm{M}$ de cada dNTP, $1 \mu \mathrm{M}$ de cada partidor $(\mathrm{F}+\mathrm{R})$ y una unidad de $\mathrm{Taq}$ polimerasa. Al producto de PCR se agregó un volumen igual de solución de formamida (95\%, $3 \%$ agua, $2 \%$ EDTA0,5M, 0,01\% azul de bromofenol y $0,01 \%$ xilen cianol) y la mezcla fue desnaturalizada a $94{ }^{\circ} \mathrm{C}$ por tres minutos y dos minutos en hielo. Se realizó una electroforesis vertical en gel de poliacrilamida al $5 \%$ (acrilamida:bis-acrilamida 29:1) en condiciones desnaturalizantes con $5 \mathrm{M}$ de urea en 1X TBE. Se corrieron en Bio-Rad Sequi-Gen GT a una potencia constante de $50 \mathrm{~W}$ durante una hora 15 minutos. En todos los geles se incluyó una escalera de peso molecular de 100 pares de bases (pb) y se cargaron tres veces consecutivas con productos de PCR de tamaños diferentes, de acuerdo al Cuadro 1.

El procedimiento de tinción consistió en sumergir el gel en diferentes soluciones como sigue: la fijación del ADN con ácido acético $10 \%$ por 20 minutos; lavado en agua destilada por 10 minutos; tinción con nitrato de plata $0,1 \%$ + formaldehído $0,15 \%$ por 30 minutos; lavado con agua destilada por 10 segundos, revelado con carbonato de sodio $3 \%$, formaldehído $0,15 \%$ y tiosulfato de sodio $0,02 \%$ por cinco minutos; y parada en ácido acético $10 \%$ por tres minutos. Todas las soluciones fueron recicladas con un máximo de cinco geles. El gel se secó por 24 horas y se obtuvo una imagen por scanner en formato JPEG y TIF (Ponciano 2004).

\section{Análisis de datos}

A partir de los patrones de bandas visualizados en los geles se codificó la información alélica en una matriz de ausencia y presencia, la cual fue utilizada para análisis de similaridad y de correspondencia en NTSYS-pc 2.02c (Rohlf 1992). Se utilizó el subprograma SIMQUAL para crear una matriz de distancias genéticas con coeficiente de Dice. Esta matriz se utilizó en el subprograma SAHN para realizar un análisis de conglomerados y construir un dendrograma basado en el método de agrupamiento UPGMA y visualizarlos con el subprograma TREE PLOT. Con el subprograma CORRESP se construyó un diagrama en tres dimensiones mostrando la distribución de las accesiones en el espacio. La diversidad genética entre los grupos identificados en el dendrograma basada en distancias genéticas de Nei (Nei 1978) se calculó utilizando el programa POPGENE versión 1.32 (Yeh et al. 1997). La matriz utilizada para este programa se construyó representando cada banda o alelo amplificado como un genotipo diferente dada la co-dominancia de los microsatélites. Como resultado, los alelos detectados se asignaron como genotipos homocigotos (AA, BB, $\mathrm{CC}$, etc.) o genotipos heterocigotos ( $\mathrm{AB}, \mathrm{AC}, \mathrm{BC}$, etc.) (Cao et al. 2006, Ordóñez y Kolmer 2006). El análisis estadístico se realizó en los módulos CO-DOMINANT DATA ANALYSIS- DIPLOID DATA-SINGLE POPULATIONS AND MULTIPLE POPULATIONS. Los parámetros de diversidad genética determinados fueron: porcentaje de loci polimórficos, frecuencias alélicas, heterocigosidad observada (Ho), índice de diferenciación genética $\left(\mathrm{G}_{\mathrm{ST}}\right)$, y flujo genético $(\mathrm{Nm})$. La diferenciación genética fue calculada con la formula de Nei (1978) $\mathrm{G}_{\mathrm{ST}}=\mathrm{D}_{\mathrm{ST}} / \mathrm{H}_{\mathrm{T}}$, donde $\mathrm{H}_{\mathrm{T}}=\mathrm{H}_{\mathrm{S}}+\mathrm{D}_{\mathrm{ST}}$ y $\mathrm{D}_{\mathrm{ST}}=\mathrm{H}_{\mathrm{T}}-\mathrm{H}_{\mathrm{S}}$, donde $\mathrm{H}_{\mathrm{T}}$ es la diversidad total para las poblaciones y $\mathrm{D}_{\mathrm{ST}}$ es la diversidad genética entre ellas (Blair et al. 2007). El flujo genético es igual al número de migrantes entre poblaciones por generación calculada en base a la formula $\mathrm{Nm}=0,25\left(1-\mathrm{G}_{\mathrm{ST}}\right) / \mathrm{G}_{\mathrm{ST}}$ (Blair et al. 2007). Otros parámetros generados de este mismo programa para cuantificar el grado de diferenciación entre y dentro de los grupos fueron: identidad genética (I), distancia genética de Nei (GD) y dendrograma UPGMA para representar las distancias genéticas entre grupos (Wagara et al. 2004).

\section{RESULTADOS Y DISCUSIÓN}

\section{Análisis de microsatélites en la colección de frijol voluble}

La Figura 1 muestra los patrones de bandas obtenidos para algunos microsatélites amplificados en un fragmento de la colección. Se pueden observan 


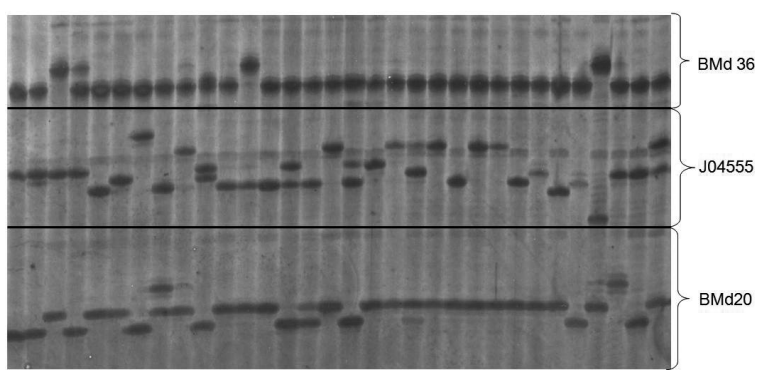

Figura 1. Patrones de segregación de tres microsatélites amplificados en varios materiales de la colección de frijol voluble de Guatemala, que muestran los alelos visualizados en gel de poliacrilamida y tinción en plata. Guatemala, marzo 2008.

claramente los polimorfismos o alelos correspondientes a diferentes marcadores o loci genéticos en un grupo de materiales (carriles). Se observó genotipos homocigotos y en algunos casos heterocigosidad. Esto último, pudo ser debido a que, contrario a lo que se cree, las accesiones no se encuentran en generaciones tan avanzadas y todavía sucede segregación o que estos materiales poseen cierto nivel de alogamia que resulta en estos patrones de heterocigosidad.

Un total de 25 alelos fueron identificados en este estudio con un promedio de 4,12 alelos por marcador. Todos los microsatélites fueron polimórficos, presentando dos o más alelos cada uno. Para todas las accesiones, incluyendo los controles, el mayor número de alelos fue revelado por el marcador J04555 el cual fue de diez. El marcador BM201 reveló el menor número de alelos, únicamente dos. Los marcadores BM160, BMd20 y BMd36 amplificaron tres cada uno, y el marcador M75856 reveló cuatro alelos. Dentro de los microsatélites de origen genómico (Cuadro 1) el promedio de alelos detectados fue de 2,67 mientras que para aquellos de origen génico fue 5,67. El marcador génico más polimórfico fue J04555 y el menos polimórfico fue BMd20. El marcador genómico menos polimórfico fue BM201. Esta diferencia indica que para este estudio los microsatélites génicos fueron más polimórficos, contrario a lo reportado en otros estudios (Blair et al. 2003, Díaz y Blair 2006, Blair et al. 2007) y pudo ser debido a que en este trabajo se amplificaron pocos marcadores. También existe evidencia de que las accesiones de frijol guatemalteco amplifican menos alelos, encontrándose loci menos polimórficos que en otras razas de frijol (Díaz y Blair 2006). Esto explicaría el hecho de que en ninguno de los casos se detectó la cantidad de alelos reportados para los marcadores utilizados, en un rango de nueve a 14 alelos (Yu et al. 2000, Gaitán et al. 2002, Blair et al. 2003).

\section{Análisis de similaridad genética y agrupamientos}

Para establecer la relación genética entre las accesiones se generó una matriz de similaridad con el coeficiente de Dice. La representación gráfica de esta similaridad o dendrograma UPGMA permitió identificar los genotipos iguales dentro de la colección pues tenían un coeficiente de similaridad igual a 1,00 (100\% de similaridad). Con el objetivo de hacer una proyección de la diversidad existente en la población, se agruparon los genotipos iguales y se tomó un representante al azar. Los 261 materiales disimilares o con genotipos diferentes conformaron una colección reducida equivalente al 46,8 \% de la colección original. Esta reducción constituye la primera recomendación de colección núcleo, puesto que identifica posibles accesiones duplicadas y su tamaño del $40 \%$ de la colección original cumple con el primer requisito que debe llenar una colección limitada. Debe quedar claro que no reemplaza a la colección inicial (Van Hintum et al. 2003), por lo que deben hacerse evaluaciones de campo para corroborar los genotipos iguales y continuar la amplificación de marcadores microsatélites combinando técnicas de detección para conformar una colección núcleo concluyente. Sin embargo, la información que proveen sus genotipos preliminares es la base para una clasificación adecuada de los materiales a pesar de la poca información fenotípica que se tiene sobre ellas. La Figura 2 muestra el dendrograma UPGMA resultante del análisis de similaridad de la colección reducida.

El análisis de agrupamientos del dendrograma divide la colección en 12 grupos principales. Con un coeficiente de similaridad de $64 \%$ se distinguen ocho grupos bien definidos (A-H). Con un $54 \%$ de similaridad se forman tres grupos (I-K). Como se esperaba, con un $24 \%$ de similaridad el control andino formó un grupo separado del resto (L). Se identificaron dos materiales que se agrupan solos, y se asignaron como Grupo E y J. Los controles silvestres de Guatemala provenientes de Chimaltenango y Sacatepéquez agruparon juntos para conformar el grupo $\mathrm{K}$ junto con la 


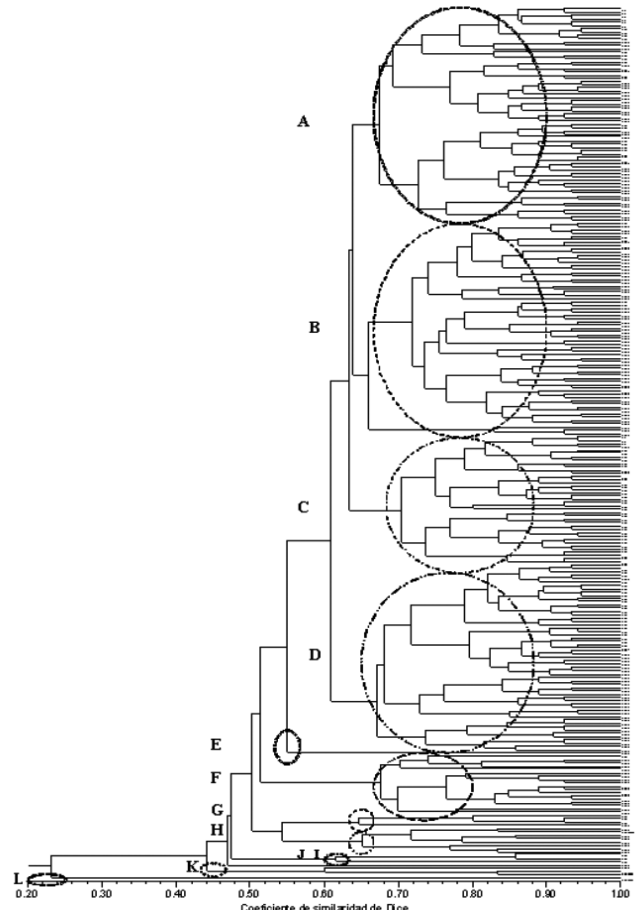

Figura 2. Dendrograma mostrando la relación entre las muestras de la colección reducida de frijol voluble de Guatemala (261 materiales) basada en el coeficiente de similaridad de Dice para seis marcadores microsatélites. Se incluyen tres controles silvestres de Guatemala y un control Andino. Las letras A$\mathrm{L}$ indican los grupos formados. Guatemala, abril 2009.

muestra más diferente de toda la colección. Esto pudo ser debido a que los controles son originarios de dos departamentos vecinos, por lo que son muy parecidos; y la muestra similar a ellos puede ser originaria de estas zonas. Por otro lado, el control proveniente de Quetzaltenango fue incluido en el grupo $\mathrm{H}$, dando lugar a la suposición de que estos materiales pueden ser originarios de esta parte del altiplano guatemalteco. Se observó también que dentro de los grupos todas las muestras agrupan por encima del $90 \%$ de similaridad.

La Figura 3 muestra el diagrama en tres dimensiones que se obtuvo con el análisis de correspondencia. Se observa que la mayoría de las muestras se agrupan muy cercanamente en sus coordenadas sobre los ejes $X$ y $Y$, no forman grupos independientes en dos dimensiones que coincidan con la agrupación observada

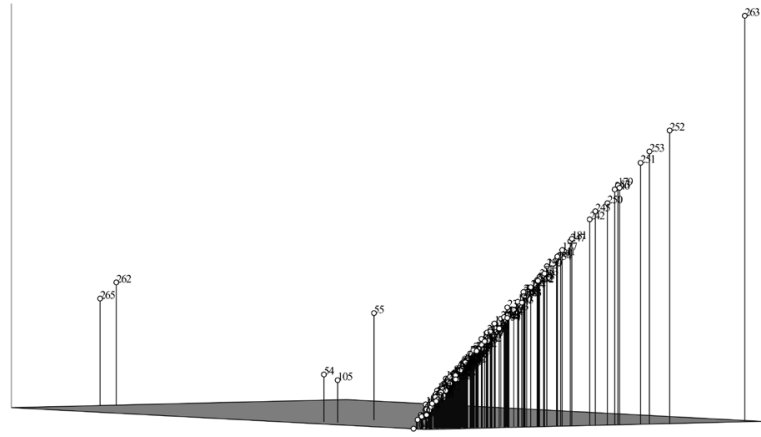

Figura 3. Análisis de correspondencia en tres dimensiones mostrando la relación entre las accesiones de la colección reducida de frijol voluble de Guatemala (261 materiales) y los controles con base en los datos de seis marcadores microsatélites. Se incluyen tres controles silvestres de Guatemala y un control Andino. La identificación de los materiales corresponde a un orden correlativo. Guatemala, abril 2009.

en el análisis de similaridad. Sin embargo, hay claras diferencias en el espacio sobre el eje $Z$ y de ahí surge su agrupación en el dendrograma. Es evidente que los materiales silvestres son diferentes de los materiales de la colección, que se cree son todos materiales cultivados. Los controles silvestres provenientes de Chimaltenango (262) y Sacatepéquez (265) se separan del grupo principal, y son muy cercanos. Esto coincide con el dendrograma al ser incluidos en el grupo $\mathrm{K}$, junto con la muestra 261. Esta última resulta ser la más diferente del grupo, y por su agrupación con las accesiones silvestres, puede ser menos evolucionada. En el grupo principal se destaca el control proveniente de Quetzaltenango (263) que agrupa con varios materiales en el grupo H. Los materiales 54 y 55 fueron incluidos en el grupo I.

La Figura 4 muestra un análisis de correspondencia en dos dimensiones de la colección en la que se han eliminado los controles, para tener una vista más detallada de la distribución espacial de los materiales. Se observa de nuevo que la diversidad genética se distribuye a lo largo del eje x (Dimensión 1) pero es difícil asociar materiales de forma que coincida con los grupos formados en el dendrograma (grupos no traslapados). La mayoría de materiales se encuentra en un grupo principal muy saturado. Se debe tomar 


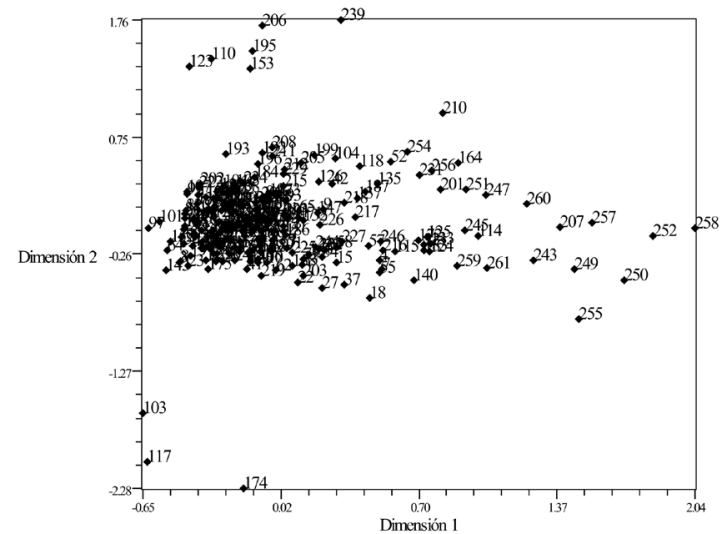

Figura 4. Análisis de correspondencia en dos dimensiones mostrando la relación entre las accesiones de la colección reducida de frijol voluble de Guatemala (261 materiales) con base en los datos de seis marcadores microsatélites. No se incluyen controles. La identificación de los materiales corresponde a un orden correlativo. Guatemala, mayo 2009.

en cuenta que esto es común cuando se trabaja con un número grande de muestras. Para discriminar con mayor exactitud entre materiales se deben incluir más marcadores microsatélites. El análisis de similaridad muestra que las colectas fueron muy amplias en número pero muy reducidas en características agromorfológicas bien definidas y de interés, como por ejemplo lugar de colecta y altitud, rendimiento o resistencia a enfermedades. Sin embargo, apoya el hecho de que el frijol es una planta autógama, y que los materiales hayan sido colectados por su hábito de crecimiento y especie.

\section{Análisis de diversidad genética}

La diversidad genética calculada por el índice de Nei para todos los genotipos de la colección reducida fue 0,4310 (Cuadro 2). Dentro de los grupos identificados, el que presentó mayor valor de diversidad fue el Grupo A $(0,3248)$ y el que presentó menor valor fue el Grupo K $(0,1574)$. Los grupos E, J y L mostraron valores muy bajos debido a que estaban conformados por una accesión. Para evitar estos valores bajos en estudios futuros, estas accesiones podrían ser agregadas al grupo más cercano. En el caso del grupo L, se

Cuadro 2. Parámetros de diversidad genética para los grupos identificados en el análisis de agrupamientos de la colección reducida de frijol voluble de Guatemala (A-K), incluyendo el control andino (L). Guatemala, mayo 2009.

\begin{tabular}{lccccccc}
\hline Grupos & N & na & ne & Ho & Nei & P & \% \\
\hline A & 65 & 2,8333 & 1,7250 & 0,2385 & 0,3248 & 6 & 100,00 \\
B & 65 & 3,0000 & 1,8658 & 0,2452 & 0,2820 & 6 & 100,00 \\
C & 39 & 2,5000 & 1,8806 & 0,1752 & 0,2512 & 5 & 83,33 \\
D & 57 & 3,0000 & 1,9218 & 0,2234 & 0,2904 & 6 & 100,00 \\
E & 1 & 1,2000 & 1,2000 & 0,2000 & 0,1000 & 1 & 16,67 \\
F & 18 & 2,5000 & 1,6825 & 0,1574 & 0,2930 & 5 & 83,33 \\
G & 4 & 1,8333 & 1,5826 & 0,0333 & 0,2900 & 4 & 66,67 \\
H & 8 & 2,0000 & 1,5821 & 0,0952 & 0,2789 & 4 & 66,67 \\
I & 3 & 1,6667 & 1,3949 & 0,1111 & 0,2407 & 4 & 66,67 \\
J & 1 & 1,0000 & 1,0000 & 0,0000 & 0,0000 & 0 & 0,00 \\
K & 3 & 1,3333 & 1,3000 & 0,0000 & 0,1574 & 2 & 33,33 \\
L (c) & 1 & 1,0000 & 1,0000 & 0,0000 & 0,0000 & 0 & 00,00 \\
Total & 265 & 4,1667 & 2,2116 & 0,2083 & 0,4310 & 6 & 100,00 \\
\hline
\end{tabular}

Abreviaciones: Número de genotipos $(\mathrm{N})$, número de alelos observados (na), número de alelos efectivos (ne), heterocigosidad observada (Ho), diversidad genética según Nei (1978), número de loci polimórficos $(P)$ y porcentaje de loci polimórficos $(\%)$, control andino (c). 
debe tomar en cuenta la posibilidad de analizar por lo menos dos controles andinos. La heterocigosidad observada fue alta tanto entre grupos $(0,2083)$ como dentro de los grupos, donde el mayor valor fue para el grupo B $(\mathrm{Ho}=0,2452)$ y el menor para el grupo $\mathrm{K}$, donde no se observaron genotipos heterocigóticos. Se esperaban valores menores de heterocigosidad debido a la naturaleza autógama del frijol. Sin embargo, apoya la evidencia presentada en otros estudios que han reportado una heterocigosidad ligeramente alta debido a que la diversidad y el nivel de entrecruzamiento es un poco mayor en los frijoles de hábito de crecimiento IV o voluble provenientes de las tierras altas de Guatemala (Beebe et al. 2000). El número de alelos detectados, los alelos efectivos y los loci polimórficos analizados para cada grupo se muestran en el Cuadro 2. Se puede notar que estos valores tienen una relación directa con el número de genotipos incluidos en cada grupo. La diversidad genética entre poblaciones relativa a la diversidad genética total fue 0,5747. Este valor indica que hubo una alta diferenciación entre los 12 grupos analizados, puesto que el $57,47 \%$ de la variación genética observada en este estudio fue debida a la diferenciación entre poblaciones, comparada con el
42,53\% de variación observada dentro de los grupos. El flujo genético total fue muy bajo (menor de 1,0000) $(\mathrm{Nm}=0,1850)$.

La identidad genética media para todos los pares de grupos fue moderadamente alta, con un rango de 0,8551 a 0,0991 (Cuadro 3), incluyendo el control andino. De todos los grupos, los A y B fueron los más similares $(\mathrm{I}=0,8551)$, mientras que los grupos $\mathbf{J}$ y $\mathrm{G}$ fueron los menos parecidos ( $\mathrm{I}=0,1978)$. Como se esperaba, el grupo L que es el control andino fue el que mostró distancias genéticas más grandes respecto al resto de los grupos (Cuadro 3). La representación gráfica de las distancias genéticas entre todos los grupos se muestra en la Figura 5. Se puede observar que los grupos A y B agrupan juntos ( $G D=0,1566)$, y a su vez agrupan con los grupos $\mathrm{C}(\mathrm{GD}=0,1681)$ y $\mathrm{E}$ (GD $=0,4414)$. Los grupos $\mathrm{D}$ y $\mathrm{G}(\mathrm{GD}=0,1861)$ agrupan juntos con el grupo $\mathrm{H}(\mathrm{GD}=0,2148)$. Los grupos I y $\mathrm{K}$ agrupan juntos $(\mathrm{GD}=0,5270)$. Los grupos $\mathrm{F}$, $\mathrm{J}$ y $\mathrm{L}$ no agrupan con otros. El grupo L control andino, mostró que es completamente diferente a todos los grupos identificados para esta colección de frijol voluble, que probablemente contiene una gran mayoría de representantes del acervo mesoamericano.

Cuadro 3. Identidad genética (I) y distancia genética (GD) calculadas según Nei (1978) para los 12 grupos identificados dentro de la colección reducida de frijol voluble de Guatemala incluyendo el control andino (grupo L). Guatemala, mayo 2009.

\begin{tabular}{lcccccccccccc}
\hline $\mathbf{G P}$ & $\mathbf{A}$ & $\mathbf{B}$ & $\mathbf{C}$ & $\mathbf{D}$ & $\mathbf{E}$ & $\mathbf{F}$ & $\mathbf{G}$ & $\mathbf{H}$ & $\mathbf{I}$ & $\mathbf{J}$ & $\mathbf{K}$ & $\mathbf{L}$ \\
\hline $\mathrm{A}$ & $* * * *$ & 0,8551 & 0,8453 & 0,8235 & 0,6431 & 0,6753 & 0,634 & 0,5992 & 0,5500 & 0,6600 & 0,4855 & 0,1981 \\
$\mathrm{~B}$ & 0,1566 & $* * * *$ & 0,8181 & 0,8287 & 0,8169 & 0,7571 & 0,6187 & 0,6110 & 0,6148 & 0,6280 & 0,6871 & 0,3313 \\
$\mathrm{C}$ & 0,1681 & 0,2007 & $* * * *$ & 0,6969 & 0,7998 & 0,5721 & 0,7180 & 0,4966 & 0,7755 & 0,4790 & 0,4582 & 0,3037 \\
$\mathrm{D}$ & 0,1941 & 0,1878 & 0,3610 & $* * * *$ & 0,6174 & 0,5722 & 0,8302 & 0,8067 & 0,4368 & 0,5007 & 0,6440 & 0,3054 \\
$\mathrm{E}$ & 0,4414 & 0,2022 & 0,2234 & 0,4822 & $* * * *$ & 0,5340 & 0,5482 & 0,5018 & 0,5890 & 0,3849 & 0,5241 & 0,3849 \\
$\mathrm{~F}$ & 0,3926 & 0,2782 & 0,5585 & 0,5583 & 0,6273 & $* * * *$ & 0,5365 & 0,6887 & 0,4402 & 0,4405 & 0,4439 & 0,0991 \\
$\mathrm{G}$ & 0,4557 & 0,4801 & 0,3313 & 0,1861 & 0,6012 & 0,6228 & $* * * *$ & 0,8103 & 0,4994 & 0,1978 & 0,4884 & 0,2769 \\
$\mathrm{H}$ & 0,5121 & 0,4927 & 0,6999 & 0,2148 & 0,6895 & 0,3730 & 0,2104 & $* * * *$ & 0,3003 & 0,2383 & 0,4938 & 0,1963 \\
$\mathrm{I}$ & 0,5979 & 0,4864 & 0,2542 & 0,8284 & 0,5294 & 0,8205 & 0,6944 & 1,2029 & $* * * *$ & 0,4463 & 0,5904 & 0,3188 \\
$\mathrm{~J}$ & 0,4156 & 0,4652 & 0,7360 & 0,6917 & 0,9548 & 0,8199 & 1,6205 & 1,4341 & 0,8068 & $* * * *$ & 0,4539 & 0,1667 \\
$\mathrm{~K}$ & 0,7225 & 0,3753 & 0,7804 & 0,4401 & 0,6460 & 0,8122 & 0,7166 & 0,7056 & 0,5270 & 0,7898 & $* * * *$ & 0,3631 \\
$\mathrm{~L}$ & 1,6188 & 1,1046 & 1,1916 & 1,1862 & 0,9548 & 2,3116 & 1,2840 & 1,6283 & 1,1432 & 1,7918 & 1,0130 & $* * * *$ \\
\hline
\end{tabular}

Abreviaciones: Grupos (GP) identificados A-L. Por encima de la diagonal se lee la identidad genética (I), por debajo de la diagonal se lee la distancia (GD). 


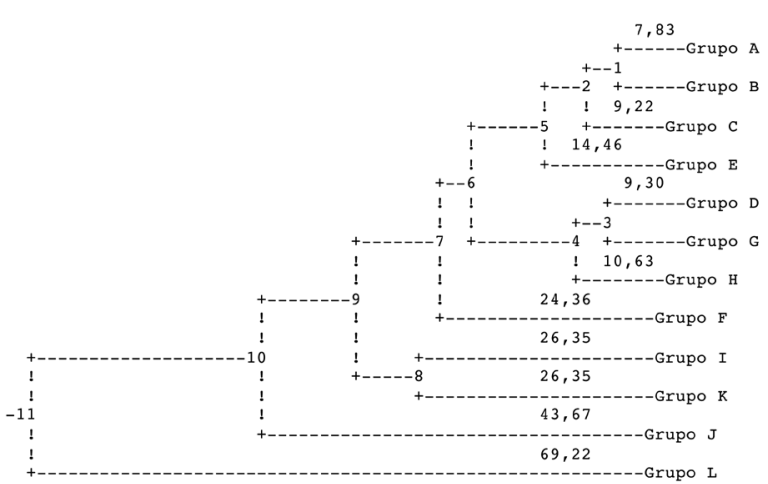

Figura 5. Dendrograma UPGMA representando las distancias genéticas calculadas según Nei (GD) entre los grupos identificados en la colección reducida de frijol voluble de Guatemala (A-L) incluyendo el control andino (Grupo L). Guatemala, mayo 2009.

\section{CONCLUSIONES}

El análisis realizado mostró que la reducción de la colección es una buena estrategia para crear una colección núcleo. Es importante resaltar que esta colección contiene una alta diversidad genética, a pesar de que las accesiones no fueron recolectadas adecuadamente. Las agrupaciones aquí sugeridas son consistentes por lo que pueden ser utilizadas como nueva clasificación de los materiales. Esta colección puede ser de gran utilidad en el estudio del frijol mesoamericano proveniente de Guatemala, para completar investigaciones previas (Beebe et al. 2000 y Díaz y Blair 2006). Se sugiere continuar saturando la matriz básica con otros 30 microsatélites utilizando métodos de detección más sensibles (por ejemplo fluorescencia). Un mayor número de marcadores detectaran más diferencias entre accesiones, dando como resultado un análisis más confiable. La evaluación de las accesiones en campo y en laboratorio permitirá confirmar los duplicados y conformar una colección núcleo útil y manejable con base en características de interés utilizando estrategias de muestreo al azar estratificado (Franco et al. 2006). Es importante ampliar el análisis de diversidad incluyendo más controles representantes de los acervos andino y mesoamericano y accesiones de la colección que pertenecen a las especies $P$. coccineus y $P$. polyanthus.

\section{AGRADECIMIENTOS}

Los autores desean agradecer al Dr. James Kelly de MSU por su apoyo científico y financiero al Programa de Mejoramiento Genético del Frijol de ICTA; y al Dr. Mathew Blair de CIAT por sus sugerencias para este estudio. También a Tomás Yancós, Daniel Sacrapal, Martin Barrios y Juan Toj por su ayuda en el campo e invernadero.

\section{LITERATURA CITADA}

Beebe, S; Skroch, P; Tohme, J; Duque, M; Pedraza, F; Nienhuis, J. 2000. Structure of genetic diversity among common bean landraces of Middle American origin based on correspondence analysis of RAPD. Crop Science 40:264- 273.

Blair, M; Pedraza, F; Buendia, H; Gaítan, E; Beebe, S; Gepts, P; Tohme, J. 2003. Development of a genomewide anchored microsatellite map for common bean (Phaseolus vulgaris L.). Theoretical Applied Genetics 107:1362-1374.

Blair, M; Giraldo, M; Buendia, F; Tovar, E; Duque, M; Beebe, S. 2006. Microsatellite marker diversity in common bean (Phaseolus vulgaris L.). Theoretical Applied Genetics 113:100-109.

Blair, M; Diaz, J; Hidalgo, R; Diaz, L; Duque, M. 2007. Microsatellite characterization of Andean races of common bean (Phaseolus vulgaris L.). Theoretical Applied Genetics 116:29-43.

Cao, Q; Lu, B; Xia, H; Rong, J; Sala, F; Spapa, A; Grassi, F. 2006. Genetic diversity and origin of weedy rice (Oryza sativa f. spontanea) populations found in North-eastern China revealed by SSR markers. Annals of Botany 98:1241- 1252.

Creste, S; Tulmann, A; Figueira, A. 2001. Detection of single sequence repeat polymorphisms in denaturing polyacrylamide sequencing gels by silver staining. Plant Molecular Biology Reporter 19:299-306.

Da Silva, J. 2003. Preliminary analysis of microsatellite markers derived from sugarcane expressed sequence tags (ETSs). Genetics and Molecular Biology 24:155-159.

Diaz, LM; Blair, M. 2006. Race structure within the Mesoamerican gene pool of common bean (Phaseolus vulgaris L.) as determined by microsatellite markers. Theoretical Applied Genetics 114:143-154. 
Franco, J; Crossa, J; Warburton, M; Taba, S. 2006. Sampling strategies for conserving maize diversity when forming core subsets using genetic markers. Crop Science 46:854-864.

Ferreira, M; Grattapaglia, D. 1998. Introducción al uso de marcadores moleculares en el análisis genético. Empresa Brasileira de pesquisa agropecuaria. Brasilia, Brasil. 221 p.

Gaitán, E; Duque, M; Edwards, K; Tohme, J. 2002. Microsatellite repeats in common bean (Phaseolus vulgaris): isolation, characterization, and cross-species amplification in Phaseolus ssp. Crop Science 42: 2128-2136.

Nei, M. 1978. Estimation of average heterozygocity and genetic distance from a small number of individuals. Genetics 89:583-590.

Ordoñez, M; Kolmer, J. 2006. Simple sequence repeats diversity of a worldwide collection of Puccinia triticina from durum wheat. Phytopathology 97:574-583.

Orellana, A; Villatoro, J; Mérida, M. 2006. Caracterización morfoagronómica y evaluación preliminar de la colección de germoplasma de frijol voluble (Phaseolus vulgaris L.) en Chimaltenango. Informe final. Guatemala, Guatemala. Instituto de Ciencia y Tecnología Agrícolas (ICTA). 17 p.
Ponciano, K. 2004. Evaluación de técnicas de extracción de ADN y de visualización para marcadores microsatélites en caña de azúcar (Saccharum officinarum L.). Tesis de Licenciatura. Guatemala, Guatemala. UVG. 63 p.

Rohfl, FJ. 1992. NTSYS-pc Numerical taxonomy and multivariate analysis systems. Versión 1.70. Exeter Publishing. New York, USA. 250 p.

Van Hintum, T; Brown, A; Spillane, C; Hodkin, T. 2003. Colecciones núcleo de recursos fitogenéticos. Boletín técnico No.3 del IPGRI. Instituto Internacional de Recursos Fitogenéticos. Roma, Italia. 44 p.

Wagara, I; Mwang'Ombe, A; Kimenju, J; Buruchara, R; Jamnadass, R; Majuwa, P. 2004. Genetic diversity of Phaeoisariopsis griseola in Kenya as revealed by AFLP and group-specific primers. Journal of Phytopathology 152:235- 242.

Yeh, FY; Boyle, R; Ye, T; Mao, Z. 1997. POPGENE, the user friendly shareware for population genetic analysis. Versión 1.32. Molecular Biology and Biotechnology Centre, University of Alberta, Alberta, USA.

Yu, K; Park, J; Poysa, V; Gepts, P. 2000. Integration of simple sequence repeat (SSR) markers into a molecular linkage map of common bean (Phaseolus vulgaris L.) Journal of Heredity 91(6):429-434. 